\title{
Politeness Strategies in Business Letters of Iranian Managers
}

\section{Seyed Javad Hoseini}

PH.D in Sociology, Teachers University and Islamic Azad University Hoviat76@gmail.com

Hamid Khosravany Fard

Ferdowsi University of Mashhad, Mashhad, Iran Hamidkhosravani8@gmail.com

\author{
Ali Khosravany Fard \\ Ferdowsi University of Mashhad, Mashhad, Iran \\ Bahmankhosravani8@gmail.com \\ Hamed Khosravani Fard \\ Ferdowsi University of Mashhad, Mashhad, Iran \\ khosravani_h@yahoo.com \\ Saeid Saleh \\ Islamic Azad University, Quchan Branch \\ s.saleh90@gmail.com
}

Doi:10.5901/ajis.2014.v3n1p239

\section{Abstract}

The purpose of this study is to find out whether there is any relationship between the cultural intelligence (hereafter CQ) and the choice of politeness strategies in the business letters. To this end, 20 Persian male managers responsible for writing English letters in import and export Iranian companies were chosen. After measuring their $C Q$ they were classified into groups according to their scores in each of the aspect of cultural intelligence, the group with higher scores and the other with lower ones. Afterwards, they were assigned a task which was the same for each writer and they were to write a letter to an imaginary company based on an occurred condition. Then the letters of each group was analyzed on the basis of Brown and Levinson's politeness taxonomy. According to the statistical analysis of the frequency of the occurrence of politeness strategies the group with the higher level of CQ used larger numbers of politeness strategies in their letters. Also bald-on strategy and avoidance strategies were the most and least frequent strategies used in their letters respectively. Moreover almost the same numbers of positive and negative strategies were used by the writers in the letters.

Keywords: cultural intelligence, Persian, English, culture, politeness strategies

\section{Introduction}

We live in an era in which anyone's life and career is to some extent dependant on languages, especially the English language through which most business and international correspondence are carried out. To be persuasive enough so as to convince one's addressee and insinuate him or her, what we already have in mind, we may need a number of different strategies by which we may have the greatest effect on others. Unfortunately, in spite of all the developments in language teaching, esp. teaching of writing, on one hand and developments in business on the other, the inter-dependent relationship between these two fields and more importantly the effect of familiarity to our addresses' culture has not deservedly received any attention.

In spite of the importance of business letters and their outstanding role in the communication process of the companies and also the customers and the companies, not much attention has been paid to the letters which are being 
exchanged. Although the major focus has been shifted toward speech, written discourse has not received the necessary consideration. Although we spend most of our time in the face to face interaction with the other people in our community, there are times that we have to make interactions via writing letters. At least once in our life, we have experienced writing letters to express our request, show our satisfaction, apply for a job, thank our mother, congratulate one of our colleagues for getting a promotion and a whole range of other subjects about which we have spent so many hours to transact what we have in mind effectively to the reader. It seems that writing a letter is less demanding in compare to in person interaction since we have lots of time to think about the way that we want to convey our meaning, but, in fact, in writing letters there is no cultural cue to find out whether we are following the cultural norms or not.

McCarthy (1991,pp.147-148) believes, unlike our knowledge of speech, our knowledge of written text has been greatly assisted by the existence of huge computerized corpora of written material such as the twenty-million word Birmingham Collection of English Text. In spite of the existence of the existence of such a huge corpora, he believes, we lack hard evidence of just how written text impinges on day-to-day life of most people. He argues that:

Both spoken and written discourses are dependent on their immediate context to a greater or lesser degree. The idea that writing is in some way 'freestanding', whereas speech is more closely tied to its context, has come under attack as an oversimplification by discourse analysts(e.g. Tarren 1982). McCarthy (1991, p.149)

What complicates the interaction via letters is that we don't always write letters to those that we share a common language. Making positive impressions on the reader with the same mother tongue as ours is much easier than the one that owns a completely different language. One of the areas that needs careful attention to cultural differences that exist between each two cultures to be effective is writing business letters, otherwise all the efforts will lead to failure due to the unfamiliarity with the rules of the culture of the target language.

To fill the gap that could be felt in this domain, this study attempts to analyze the business letters which affect the life of business managers to a large extent and see how the politeness strategies being used by them in the letters of complaint differ between those with a high CQ and those with a lower rate of CQ.

\subsection{Cultural Intelligence}

Due to the rate of globalization of organization and also diversity of workforce demography in today's polyglot's world and global economy especially in multicultural societies, it is of utmost important to know the reason why some individuals react more effectively and positively in culturally diverse settings than others. One of the skills that is frequently talked about in the twenty-first century is the ability to adapt constantly to different people from diverse cultures and the ability to manage the interconnectedness of today's world. The global workplace requires individuals to be sensitive to different cultures, to interact appropriately with people from different cultures, and to analyze new cultures as they are encountered. To do all this, individuals, whether they are at home or abroad, need cultural intelligence.

In contrast to what Friedman (2005) believes that globalization has made the world seem smaller and 'flat' incultural diversity creates challenges for individuals and organizations, making the world 'not so flat' after all. What is becoming more important in today's global business world is the ability to interact effectively with different people in multiple cultures. This ability is labeled cultural intelligence. Cultural Intelligence or CQ is a new domain of intelligence that is increasingly relevant to today's global economy. Difficulty in adjusting to cultural setting and inability to interpret the cultural cues creates a negative impression. How is it that some individuals are more successful than others in a crosscultural business situation? How can some people travel easily from country to country and effectively conduct business, while others may only be effective in a few countries or completely ineffective outside their home country?

Earley and Ang (2003) developed the construct of cultural intelligence (CQ) based on contemporary theories of intelligence (Sternberg, 1986). In fact, CQ is individual's capability to function and manage effectively in culturally diverse settings, also it's a multidimensional construct targeted at situations involving cross-cultural interactions arising from differences in race, ethnicity and nationality.

According to Thomas and Inkson (2004, pp. 182-183) CQ is defined as multifaceted competency consisting of cultural knowledge, the practice of mindfulness, and the repertoire of behavioral skills. Schmidt and Hunter $(2000$, p. 3$)$ defined Cultural intelligence (CQ) as an individual's capability to function and manage effectively in culturally diverse settings, which is consistent with definition of general intelligence as 'the ability to grasp and reason correctly with abstractions (concepts) and solve problems.'

Sternberg and Grigorenko(2006)believe that research on CQ has focused primarily on conceptual theorizing. Conceptual distinctions between CQ, a culture-free etic construct, and the traditional view of intelligence that is culture- 
bound and emic is discussed by $\mathrm{Ng}$ and Earley (2006),also Triandis (2006) discussed theoretical relationships between CQ capabilities and forming accurate judgments; Brislin et al. (2006) discussed CQ as critical for expecting and addressing the unexpected during intercultural encounters; Earley and Peterson (2004) developed a systematic approach to intercultural training that links trainee CQ strengths and weaknesses to training interventions. Janssens and Brett (2006) advanced a fusion model of team collaboration for making culturally intelligent, creatively realistic team decisions.

Sternberg (1986) has proposed an integrative framework containing different 'loci' of intelligence within the person. Those mental capabilities which reside in the head are metacognition, cognition, and motivation and those overt capabilities which are behavioral.

Metacognitive CQ reflects the processes individuals use to acquire and understand cultural knowledge. According to Sternberg (1986) it refers to refers to control of cognition: the processes individuals use to acquire and understand knowledge.

Cognitive CQ is general knowledge and knowledge structures about culture and is consistent with Ackerman's (1996) intelligence-as-knowledge concept, which argues for the importance of knowledge as part of the intellect.

Motivational CQ is magnitude and direction of energy applied toward learning about and functioning in crosscultural situations and as (Ceci, 1996) believes motivational capabilities are critical to 'real world' problem solving.

Behavioral CQ is the capability to exhibit appropriate verbal and nonverbal actions when interacting with people from different cultures and in the Sternberg's $(1986$, p. 6) words what people do rather what they think.

\subsection{Politeness theory by Brown \& Levinson}

According to Hall (1959) communication is culture, and culture is communication. In other words the way we organize our lives is part of a network of communication and those who would function within a society other than their own must learn its culture as well as its linguistic code. The reason for misunderstanding and culture shock is largely because of the different modes of thought and cultural patterns between two countries rather than the linguistic incompetence of the user of the language. Effective interlingual communication is always possible, despite seemingly enormous differences in linguistic structure and cultural features (Eugene A.Nida, 1969, P.483). According to (Saville-Troike, 1996, p.363) the ability to successfully comprehend and produce speech acts in a given language is considered a major component of communicative competence, i.e. the social and cultural knowledge which is presumed to enable speakers to use and interpret linguistic forms in context. In addition to the ability to comprehend and also produce speech acts, the interlocutors must be armed with a social device which is called politeness to make the most effective communication.

Traditionally the study of politeness phenomena has traditionally been primarily concerned with individual choices in spoken face-to-face interaction. The formal theoretical construct of politeness is based on the speech act theory and Grice's theory of conversation along with a restricted understanding of Goffman's (1955/1967) notion of 'face'. Since almost any function performed via linguistic means constitutes a potential threat for some aspect of the speaker's and/or the addressee's public self-image, most speech acts are considered face threatening (FTAs). Politeness is as a "discursive conversational contract" that depends heavily on tacit understandings of the terms and conditions of that contract (Murphy, 1999, p. 233). Also Lakoff (1989) defines politeness as a social device to avoid conflict in human interaction. The concept of politeness is linked to the notion "face" by Brown and Levinson (1978). They defined the notion of "face" as the public self-image that every person wants to claim for himself consisting of two related aspects: a) Negative face: the basic claim to territories, personal preserves, rights of non-distraction- i.e. to freedom of action and freedom from imposition; b) Positive face: the positive consistent self-image or personality (crucially including the desire that this self-image be appreciated and approved of or claimed by 'interactants'). (Brown \& Levinson, 1978, p. 66).

Tracy explains, "positive face concerns the desire to be appreciated and approved of by selected others. Negative face concerns a person's want to be unimpeded and free from imposition". (Tracy, 1990, p.210) An example of a speech act that threatens the hearers' $\left(H^{\prime} s\right)$ negative face would be a request, because this means that the speaker (S) is impeding on $\mathrm{H}$ by asking $\mathrm{H}$ not to do what $\mathrm{H}$ wants, but rather to do what $\mathrm{S}$ wants(Fasold,1990,p.161). On the other hand, a speech act that threatens H's positive face would be "a contradiction or expression of disagreement, which means the speaker thinks there is something wrong with an opinion held by the hearer".(Fasold,1990,p.161). Apart from making a claim, other necessary acts such as criticism, naming things, speculating or asserting one's priority, also threaten face (Myers,1989).

Goffman (1967) believes that in social interaction, people "perform" in a certain way to present their self-image and give a certain impression of themselves to other people (p.22). Because of the conscious or unconscious awareness of the interlocutors of the vulnerability of face, they both try to maintain each other's "face" accordingly. Brown and Levinson 
(1987) also point out that face is something which must be constantly attended to in interaction, something which is emotionally invested and that can be lost, maintained, or enhanced. To maintain each other's face, both interlocutors tend to mitigate the potential effects of the FTA on their face. The mitigation strategies employed by speakers are labeled politeness strategies and involve five main categories (1) bald on record, which represents the most direct and efficient ways to perform a speech act and is supposed to be employed when no risk for face is involved,(2) positive politeness consisting in linguistic strategies that express solidarity and involvement, thus emphasizing in-group relations,(3) negative politeness, realized by means of linguistic strategies which indicate that the speaker does not want to curtail the addressees' freedom of action,(4)off record involving indirect uses of the language where the speaker's communicative intention is vague or ambiguous. Off record strategies involve ambiguous intentions (Garcés-Conejos \& SánchezMacarro 1998, p.175). And, (5) do-nothing reflecting the speaker's choice not to perform the FTA at all. They also claimed that the degree of risk for the different aspects of face (or weight of imposition)involved in the FTA is determined by the cumulative effect of three social variables that are claimed to be universal,i.e.(i)the social distance (D) between participants, (ii)the relative power (P)between them and (iii)the absolute ranking(R)impositions in each particular society. However Brown and Levinson believed explained "in any particular society we would expect [face] to be the subject of much cultural elaboration" (p. 13).

One crucial factor that makes Brown and Levinson's (1987) model as a reliable source for analyzing politeness strategies may be considered as its universality and the fact that almost all of our daily interactions are under their impact. Another significant point of this model is its emphasis on recognizing the target cultures based on the three social variables that provoke FTAs in any interaction: the social distance between participants, their relative power, and the ranking of imposition in any specific culture. Analyzing culture in this model is facilitated by focusing on the amount of positive and negative strategies and weighing them against one another in each culture to find out in which one solidarity or imposition rule more. By a similar token, Scollon and Scollon (1981) pointed out that while in different cultures negative politeness determines the seriousness of the imposition, the positive one emphasizes the general nature of relationships among interactants. Therefore, Brown and Levinson's theory was chosen in this study since it seems to account adequately for the present data in description of linguistic strategies used in the letters when analyzing the linguistic interaction.

\section{Purpose of the Study}

This study aims investigating the relationship between cultural intelligence and the politeness strategies used in business letters. Therefore this study is an attempt to find the answer for the following questions:

1. Is there any relationship between the cultural intelligence and the use of politeness strategies in the business letters?

2. Which of these two groups used larger number of politeness strategies in their letters?

3. Which of the politeness strategies are the least used by the English letter writers?

4. Which strategies are the least used by those with the lower level of general CQ?

5. Which strategies are frequently used by those with higher level of general CQ?

6. Which strategies are highly used by the writers with the lower of CQ in each respect?

7. Which strategies are frequently used by those with higher level of general CQ?

\section{Methodology}

\subsection{Participants}

Participants were 20 Persian male adult business letter writers, all of them aged between 22 and 40 and worked for the Iranian import and export companies, especially import companies, in Mashhad city in Iran. To limit the effect of gender on the result of the study, only male writers were chosen in this research study.

\subsection{Instrument}

As the first phase of this study the participants' CQ were measured by using a CQ questionnaire. The questionnaire by which the researchers assessed CQ with the 20-item, four-factor model was developed and validated by Ang and colleagues (2004). The inventory includes four items for metacognitive CQ, six for cognitive CQ, five for motivational CQ, 
and five for behavioral CQ.

Sample items include "I am conscious of the cultural knowledge I apply to cross cultural interactions" for metacognitive CQ; "I know the legal and economic systems of other cultures" for cognitive CQ; "I enjoy interacting with people from different cultures" for motivational CQ; and "I change my verbal behavior when a cross-cultural interaction requires it" for behavioral CQ. The CQ questionnaire used in this study is brought in the appendix 1.

Then the participants classified for 5 times to two groups based on their score in each aspect of the CQ. Afterwards they were to write a letter on the basis of an occurred condition which was the same for all the writers. The task that they were provided with is brought in the appendix 1.

As mentioned earlier we are to analyze the written letters on the basis of the politeness strategies which was proposed by Brown and Levinson (1987), for instance to see which of the five types of the strategies to save face of the readers of the letters are used by those writers that have higher level of behavioral CQ in compare to those that have lower level of that.

\section{Results}

Based on the complete analysis of the letters based on the brown and levinson's model of politeness strategy, the frequency and percentage of each of the politeness strategies was calculated and displayed in the following tables. The data presented in the tables will further analyzed in more details.

Table 1. Frequency of Strategies Used by each group in relation to their general CQ

\begin{tabular}{|c|c|c|c|c|c|c|c|c|c|c|c|}
\hline & \multicolumn{2}{|c|}{ Bald-on } & \multicolumn{2}{c|}{ Positive } & \multicolumn{2}{c|}{ Negative } & \multicolumn{2}{c|}{ Off-record } & Avoidance & Total \\
\hline Lower level & 65 & $\% 59$ & 14 & $\% 12$ & 20 & $\% 18$ & 9 & $\% 8$ & 2 & $\% 2$ & 110 \\
\hline higher level & 25 & $\% 19$ & 46 & $\% 36$ & 40 & $\% 31$ & 11 & $\% 8$ & 5 & $\% 4$ & 127 \\
\hline
\end{tabular}

Table 2. Frequency of Strategies Used by each group in relation to their Metacognitive CQ

\begin{tabular}{|c|c|c|c|c|c|c|c|c|c|c|c|}
\hline & \multicolumn{2}{|c|}{ Bald-on } & \multicolumn{2}{c|}{ Positive } & \multicolumn{2}{c|}{ Negative } & \multicolumn{2}{c|}{ Off-record } & Avoidance & Total \\
\hline Lower level & 35 & $\% 33$ & 26 & $\% 25$ & 30 & $\% 28$ & 12 & $\% 11$ & 1 & $\% 1$ & 104 \\
\hline higher level & 55 & $\% 41$ & 34 & $\% 25$ & 30 & $\% 22$ & 8 & $\% 6$ & 6 & $\% 5$ & 133 \\
\hline
\end{tabular}

Table 3. Frequency of Strategies Used by each group in relation to their Cognitive CQ

\begin{tabular}{|c|c|c|c|c|c|c|c|c|c|c|c|}
\hline & \multicolumn{2}{|c|}{ Bald-on } & \multicolumn{2}{c|}{ Positive } & \multicolumn{2}{c|}{ Negative } & \multicolumn{2}{c|}{ Off-record } & Avoidance & Total \\
\hline Lower level & 32 & $\% 29$ & 36 & $\% 33$ & 26 & $\% 24$ & 11 & $\% 10$ & 3 & $\% 3$ & 108 \\
\hline higher level & 58 & $\% 45$ & 24 & $\% 18$ & 34 & $\% 26$ & 9 & $\% 7$ & 4 & $\% 3$ & 129 \\
\hline
\end{tabular}

Table 4. Frequency of Strategies Used by each group in relation to their Motivational CQ

\begin{tabular}{|c|c|c|c|c|c|c|c|c|c|c|c|}
\hline & \multicolumn{2}{|c|}{ Bald-on } & \multicolumn{2}{|c|}{ Positive } & \multicolumn{2}{|c|}{ Negative } & \multicolumn{2}{|c|}{ Off-record } & \multicolumn{2}{|c|}{ Avoidance } & Total \\
\hline Lower level & 60 & $\% 59$ & 15 & $\% 14$ & 12 & $\% 12$ & 8 & $\% 8$ & 6 & $\% 5$ & 101 \\
\hline higher level & 30 & $\% 22$ & 45 & $\% 33$ & 48 & $\% 35$ & 12 & $\% 9$ & 1 & $\% 1$ & 136 \\
\hline
\end{tabular}

Table 5. Frequency of Strategies Used by each group in relation to their Behavioral CQ

\begin{tabular}{|c|c|c|c|c|c|c|c|c|c|c|c|}
\hline & \multicolumn{2}{|c|}{ Bald-on } & \multicolumn{2}{c|}{ Positive } & \multicolumn{2}{c|}{ Negative } & \multicolumn{2}{c|}{ Off-record } & \multicolumn{2}{|c|}{ Avoidance } & Total \\
\hline Lower level & 42 & $\% 36$ & 35 & $\% 30$ & 25 & $\% 21$ & 10 & $\% 8$ & 4 & $\% 4$ & 116 \\
\hline higher level & 48 & $\% 39$ & 25 & $\% 20$ & 35 & $\% 29$ & 10 & $\% 8$ & 3 & $\% 2$ & 121 \\
\hline
\end{tabular}

According to the analysis of their letters by taking into account the brown and levinson's politeness strategies as the model of the analysis, the researchers examined which of the strategies are frequently used in the letters of the two groups and the kind of the strategy is brought under the heading of each one. For instance after the classification of the participants according to their general CQ to the two groups with lower and higher CQ, their letters were examined to find out which strategies are commonly used in the letters of this group and also which type of each of the five kinds of 
politeness strategies presented by Brown and Levinson's model is least resorted to in these letters. Here off-record and avoidance strategies are not presented because they don't have any subcategory according to the criterion model of analysis.

According to the statistical data in the above tables which presents the frequency of occurrences of each of the five aforementioned politeness strategies, it can be inferred with a high degree of certainty that maybe due to the cultural factors and the participants' background knowledge avoidance strategies are the least used among the others. For instance the frequency of avoidance strategies, as shown in Tables 1 to 5, for the groups with lower general, metacognitive, cognitive, motivational, and behavioral CQ are $\% 2, \% 1, \% 3, \% 5$ and $\% 4$ respectively. The frequency of the occurrences of the avoidance strategies, as shown in Tables 1 to 5, for the participants with the higher level of general , matacognitive, cognitive, motivational and behavioral CQ are $\% 4, \% 5, \% 3, \% 1$, and $\% 2$ respectively, which are very low in compare to the frequency of the occurrences of other politeness strategies in their letters. Also the same is true about the other groups with higher level of CQ. On the whole, irrespective of the participants' CQ scores and the classification of the participants into the two groups, avoidance strategies are the least applied strategies among the other politeness strategies. Among all the types of politeness strategies, the politeness strategy that takes the forth rank among the other strategies according to their occurrences are off-record strategies. As presented in the Tables1 to 5 ,it's used about $\% 8, \% 11, \% 10, \% 8$,and\%8 by the group with lower level of general, metacognitive, cognitive, motivational, and behavioral $\mathrm{CQ}$, respectively.

Moreover, it can be inferred from the data presented in the tables that bald-on strategies are frequently used by the participants of this study to the point that sometimes it's used more than other strategies for instance, as shown in Table1,for the group with lower general CQ about \%59 of all the strategies which is more than half of the frequency of the occurrences of other four strategies.

Interestingly there were several letters that the researchers found no trace of the presence of the bald-on strategies. In contrast to the bald-on and off-record strategies which were not utilized in several letters, no letter was found without the presence of positive and negative politeness strategies.

By taking a close look at the data presented in the Table1, it can be inferred that the group with the higher level of general CQ applied more numbers of positive politeness strategies in compare to the other group which used more numbers of negative strategies. Also, there's a huge gap between the occurrences of bald-on strategies by the two groups which is $\% 59$ for the group with the lower level of CQ and \%19 for the group with the higher level of CQ. Examining and comparing the frequency of the occurrences of the other politeness strategies in Table1 show that more numbers of strategies are used by the group with higher level of general CQ. In fact $\% 36, \% 31, \% 8$,and $\% 4$ of the frequency of the use of the politeness strategies in the group with higher level of general CQ stands against the $\% 12, \% 18, \% 8$,and $\% 2$ of the frequency of these strategies in the group with lower level of general CQ, for the positive, negative, off-record, and avoidance strategies respectively.

As mentioned previously in the methodology section of this research paper, to compare and contrast the use of the politeness strategies in each level the participants were classified into two groups, one with lower and the other with higher level of CQ for each type of politeness strategies. To the researchers' interest, it was found out that except for the letters of four of the participants with higher level of general CQ, the other letters were always among the 10 letters with higher level of metacognitive, cognitive, motivational, and behavioral CQ. Comparison of the Tables 2 and 3 for metacognitive and cognitive CQ shows how close the frequencies of the occurrences of different strategies are between the two groups. For instance the percentage of the occurrences of bald-on ,positive, negative, off-record and avoidance strategies for the group with higher level of metacognitive CQ based on Table2 are $\% 33, \% 25, \% 28, \% 11$,and \%1 respectively. And the percentages for the groups with lower level of metecognitive CQ are $\% 29, \% 33 \%, \% 24, \% 10$, and $\% 3$ for each of the politeness strategies. And also for the group with higher levels of cognitive CQ, as presented in table3, the percentages are $\% 41, \% 25, \% 22, \% 6$, and $\% 5$ respectively and for the group with lower level of cognitive CQ are $\% 45, \% 18, \% 26, \% 7$, and $\% 3$.

In addition to the analysis of the letters according to the frequency of the occurrences of politeness strategies which is part of the objective and statistical analysis of the letters ,the researchers examined the letters with respect to the classification of groups to see which strategies are more frequently used in their letters and also examples are provided for each of them.

\subsection{General CQ:}

Regarding the groups with higher level of general CQ, as shown in Table1, two off-record strategies were mostly used in 
the by participants' letters of this group. The expression of their request was reflected by the showing of the feeling of great urgency and desperation to the point that in some parts of the letters no evidence of attempt made to minimize the threat to the readers' face is observed. In one of the letters the following sentence was used:

Based on the above order you had to deliver my merchandise on May 24th.

Another case which proves the presence of bald-on strategies in the letters this group was the use of expressions that expressed great efficiency was needed in satisfying the participants' requests as if the lack of effort to save the face of the readers of the letters is obvious. Here's one of the examples:

During these two weeks we have the largest numbers of customers so hurry in sending us the merchandise.

The researchers found that positive politeness was expressed through the optimism that was commonly used in their letters by which the writers are seeking to minimize the threat to the readers' face.

We're sure that due to some unpredictable problem that has occurred, you didn't send us what we want on due time.

Another commonality of these letters with respect to the application of negative strategies is the use of obviating structures, like nominalizations, passives, or statements of general rules.

I hope offense will not be taken. Certainly you remember the conditions in the contract abut the consequence of the belated delivery of the product.

So based on the strategies outlined by brown and Levinson (1978) the readers' negative face was of high concern to the writers so the principle of distancing is applied in this respect which is a feature of negative politeness strategies.

Analysis of the letters of those with lower level of CQ shows that they expressed their request in a way to show that great efficiency was necessary in which again that the lack of effort to save the face of the readers of the letters is obvious. This attribute is compatible with the bald on-record strategies.

Every day we're losing the faith we have planted in the people's heart. We'll be a bankrupt in the next week.

The expression of politeness strategies by applying two approaches in their letters was common. One of them was the attention to the readers' interests, needs, and wants.

This is the first time since we have initiated our business that you were not successful in practicing what you preach. Is there anything our company can do for you?

And also the other was the expression of optimism in the content on the letters' of this group but in contrast to the writers' with lower level of general CQ, it was used for several times in the content of their letters.

Your punctuality is approved to us during all the years we have worked with each other.

Actually four types of negative politeness strategies were used in the letters of this group. The most common was that they expressed their complaint and request in an indirect way to save the readers' face.

Would you know how much damage our company will be inflicted by the late delivery of the product?

The second most common was the numerous uses of hedges or questions in their letters which were eye-catching. The sizeable damage to our company should be compensated.

The third one was the use of words or expressions to minimize the imposition imposed on the readers of the letters.

It's not that difficult for you powerful company to satisfy our need.

And the last most common was the use of Apology in advance of expressing their requests especially the 
compensation that they asked for the delay in the delivery of the product.

I'm sorry; it's a lot to ask, but can you compensate the loss that our company has taken due to the inconvenience?

\subsection{Metacognitive CQ:}

The same analysis was carried out for the other aspects of $C Q$ and the use of politeness strategies in the letters of those with lower and higher level of metacognitive CQ was analyzed.

The results of the analysis of the letters of those with higher level of CQ showed that the bald-on strategies revealed themselves in one of these two ways: low or no desire to maintain the readers' face due to the existence of direct order of their requests and also expression of great urgency or desperation in their letters was expressed.

You should have delivered my machinery on time, but you didn't.If you want to keep me as your client in future, you should pay back me10 percent of the price of CNC since I paid this to my costumers because of my delay to deliver their orders, otherwise I will never collaborate with your company for my other needs in future

The solidarity in-group identity markers were the most common type of positive politeness strategies observed in their letters.

Your company has been the best partner during these years for us and we know it by it's punctuality as a constant feature of it.

Expression of pessimism was commonly used in their letters which is a type of negative politeness strategy.

I know that it's not possible for your company to deliver the product till next week.

Analyzing the letters of those with lower level of matacognitive CQ shows that exaggeration in the writers' interest in the readers and their interests as a type of bald-on strategy was commonly used in their letters.

Keep your promise and send the factory what we ordered and we will introduce you as our teammate against the rivals.

Offerings and promises to the target companies to compensate the harm imposed on them due to the delay in the delivery of the product was the type of positive politeness strategy revealed in the letters.

You know that we have customers all over the world so if you save and respect our reputation, we will do our best to the same for you.

Frequent use of obviating structures, like nominalizations, passives, or statements of general rules was noticed in their letters . The most frequent structures which were applied by the writers were the passive structures. These are one of the common features of these letters and one type of negative politeness strategies.

Swift response to our request is required other wise our deal with your company will be stopped.

\subsection{Cognitive $C Q$ :}

The analysis of the letters of the group with higher level of cognitive CQ shows that they commonly applied exaggeration in their interest in the readers and their interests which is a kind of bald-on strategy.

The future of your company is of utmost importance to us. So try not to lose us as your customer.

In the letters of the same group the inclusion of both the writers and the readers in the statements was clear.

If we can help each other in the case that some unexpected problem happens, our ties will be strengthened.

Negative politeness was also exhibited by the use of expressions that show the writes' pessimism in the satisfaction of their requests. 
Unfortunately in this time of the year your company is hard up to compensate our loss.

In the letters of the group with the lower level of cognitive CQ, bald-on strategy is presented through the use of face saving acts in the interest of the readers.

Keep our production line of the factory active to save the life of your own company.

In addition, notification of great urgency was the second most common bald-on strategy used in the letters of this group of writers.

Two of the most common politeness strategies observed in the letters of this group are the offering of gratitude for the compensation in advance and making an apology for the demand which is going to be imposed on the readers. The following examples show each of these two strategies respectively.

It's necessary to express my gratitude for your attention to my request in advance.

In contrast to the loss to our company, we didn't lose our faith in your company.

The attempt to minimize the effect of the imposition could bee seen in their letters as the evidence for the presence of negative politeness strategies.

Our request to pay us back $\% 20$ of the contract due to the caused inconvenience is a herculean task for you.

\subsection{Motivational CQ:}

In the letters of the group (10 writers) with the higher motivational CQ, it was figured out that great efficiency is expressed in their letters by using statements in the form of an order which is most often utilized in situations where the writer has a close relationship with the audience, such as family member or close friends.

\section{Dear friends we expect you not to violate the general and world wide rules of business.}

The use of politeness strategies is observed by the expression of optimism in their letters to minimize the threat to the readers' positive face.

Such problems occur to test the loyalty of the two partners to each other.

Also the use of Use solidarity in-group identity markers in their letters was common as one type of positive politeness strategies.

We are two of the closest allies all over the world this is such a strong relationship that helps us in gaining fame.

Making apology for the imposition which is to be made to ask for the compensation is the most frequent type of negative politeness strategy used in their letters.

Accept our apology for asking you to provide us with the compensation due to our losing of our customers.

In the letters of the group (10 writers) with the lower motivational CQ, the researchers figured out that in the writers' view doing face-threatening act is in the interest of the readers of the letters.

Your quick delivery of the product we needed is to your benefit and will keep your customers.

Expression of optimism in the content of their letters and also exaggeration in the interest of the readers of the letters was observed as types of positive politeness strategies. The following examples show each of these two respectively.

We believe in your doing your words in contrast to what has occurred. Believe it or not, you're losing some of your constant customers inside Iran because we also guide other small companies about the reputations of the target companies. So to save your face save our face and deliver our order. 
Negative politeness strategies that were common among all the letters of this group - writers with higher level of motivational CQ - are the use of hedges or questions in their letters, making apologies for the asking for the compensations due to the delay in the delivery of the product, and the last most common one was the use of indirect orders to ask for the cause of the delay in the delivery of the merchandise. Below examples present each of these strategies respectively.

Is it possible for you to implicate the conditions in the contract in the case of late delivery of the product mentioned in the contract?

Do you know how it is possible to response to our customers after so much advertisement about importance of time and prompt delivery of our company?

\subsection{Behavioral CQ:}

In the letters of the group (10 writers) with the higher behavioral $\mathrm{CQ}$, the researchers observed the use of statements that express great urgency which is a type of bald-on strategy.

Don't hesitate to send us what we ordered because we're in a state of desperation.

As a common type of positive politeness strategy attention to the interest and needs of the readers of the letters was expressed in their letters.

It's to your benefit that you supply our company with the merchandise that we ordered in two weeks because our customers are your customers too.

Of different types of negative politeness strategies pessimism in the request for the compensation was used in their letters.

Your company doesn't have the budget to compensate for the delay in sending us the merchandise on time?

In the letters of the group (10 writers) with the lower behavioral CQ, the most common type of bald-on strategy observed in the letters was the use of statements that emphasize great efficiency on the part of the readers to satisfy the requests of the writers of the letters.

I.B.M co must compensate the loss otherwise we lose lots of our customers.

Two of the most common types of positive politeness strategies that were expressed in the letters of this group are the use of particular devices to express solidarity with the correspondents for example in-group identity markers could be seen in the content of their letters and also expressing that both writers and readers are included in the activity which helps to make the readers feel good about themselves, their interests or possessions, and are most usually used in situations where the audiences know each other fairly well.

Our companies are as close as two twin brothers with the same mother tongue that will live together forever.

It's a kind of burden on the shoulders of our companies to keep our promises based on the contract we have agreed upon.

Apologizing for the imposing of the request which is the delivery of the merchandise and also asking for the compensation due to the inconvenience caused by the writers of the letters of this group was the most frequent and common type of negative politeness strategies in their letters.

I hereby apologize for asking you the compensation due to the delayed delivery of the product.

To sum, according to the statistical results of the study which was mainly concerned with the frequency of the occurrence of the politeness strategies as illustrated in the above tables, it should be pointed out that avoidance strategies are the least used among other politeness strategies with regard to all of the aspects of CQ and also the groups considered in this study.

Also the number of strategies used by the group with the higher level of $C Q$ is more than the number of strategies 
used by the other group.

There exists a great similarity between the frequency of the occurrence of the strategies in Table 1 and Table 4.In other words, comparing the frequency of the occurrences of politeness strategies between the groups with higher levels of general and cognitive CQ and also those with lower levels of the general and cognitive CQ shows the similarity of their applying of different types of politeness strategies.

The highest distinction between the total number of strategies used by the group with lower CQ and higher CQ exists in the Table 4.It means that the group with the higher level of cognitive CQ has applied the highest number of politeness strategies and the counterpart group, managers with the lower level of cognitive $C Q$, has applied the lowest number of politeness strategies in their letters.

Bald-on strategies are the most frequently used strategy among the other strategies, with frequency of 90.

Avoidance strategy is the least used strategy among the other strategies, with frequency of 7 .

After examining each of the letters individually, the researchers figured out that there was numerous use of only one type of the politeness strategies in their letters. For instance in one of the letters the writer applied only one of the five types of strategies which was off-record strategy for more than five times.

\section{Discussion}

This study was conducted to examine the kind of politeness strategies which are being used in the business letters of the Iranian managers responsible for writing letters in import and export companies and also to find out the relationship between the participants' (cultural intelligence) and the kind of politeness strategies they apply in their complaint letters, as a response to an imaginary situation. To keep a balance and avoid being distracted by the topic of the letters, we decided to limit the topic that the participants were to write about to complaint letters. As a matter of fact each of the participants were given a task in which a situation was discussed for them and they were supposed to respond to the situation by writing a letter to the imaginary company that has caused them a particular inconvenience.

Moreover the numbers of politeness strategies are counted based on the theory proposed by Brown and Levinson's (1987) model. There are four types of strategies which are incorporated in the interaction between the interlocutors: 1) bald on record, 2) positive politeness, (3) negative politeness, 4) off record, and 5) do-nothing. Also the model of CQ used to measure the participants CQ was a questionnaire developed by Ang et al. (2007) which is grounded on the Sternberg's integrative framework of intelligence which includes: metacognitive, cognitive, and motivational and behavioral CQ.

Cultural intelligence scale (CQS) which includes 20 items with four factors is developed by Ang et al. (2007) and its psychometric properties are empirically examined. The psychometric properties which are examined are cross-validation, generalizability across time and generalizability across countries. Furthermore, substantive predictions based on the integration of intelligence and intercultural competencies literatures were also tested. Cross-validation analyses provided strong support for the validity and reliability of CQs across samples, time and countries.

As the outcomes of the study revealed, the politeness strategies which were used in the expression of the complaint to the target company by those with higher level of CQ were different from those of the participants with lower level of CQ. On the whole, those participants with higher level of CQ used more number of politeness strategies in their letters. Also analysis of tables reveals that Tables 2 and 3 (metacognitive and cognitive CQ), and also Tables 1 and 4 (general and behavioral CQ), regarding the number of times each of the strategies are occurred in the letters are really close together. Further research is suggested to be carried out in other context with other participants to see whether the same results will be reached or not. Interestingly the greatest distinction was found between those with higher and lower level of cognitive CQ regarding the number of times they resorted to politeness strategies. Due to the fact that, in no other study attempt is made to find the relationship between the politeness and CQ, further research is required to substantiate the results of this study.

\section{References}

Ackerman, P. L. (1996). A theory of adult intellectual development: Process, personality, interests, and knowledge. Intelligence, 22(2), 227-257.

Ang, S., Van Dyne, L., Koh, C.,\&Ng, K. Y. (2004, August). The measurement of cultural intelligence. Paper presented at the Annual Meeting of the Academy of Management, New Orleans, LA.

Brislin, R., Worthley, R., \& MacNab, B. 2006. Cultural intelligence: Understanding behaviors that serve people's goals. Group and Organization Management, 31: 40-55. 
Brown, P. and Levinson S. (1987). Politeness: Some universals in language use. Cambridge: Cambridge University Press.

Ceci,S.J.(1996).On intelligence: A bio ecological treatise on intellectual development. Cambridge, MA: Harward university press.

Earley, P. C., \& Ang, S. (2003). Cultural intelligence: Individual interactions across cultures. Palo Alto, CA: Stanford University Press.

Earley, P. C., \& Peterson, R. S. (2004). The elusive cultural chameleon: Cultural intelligence as a new approach to intercultural training for the global manager. Academy of Management Learning \& Education, 3(1), 100-115.

Fasold,R.(1990). The sociolinguistics of Language. Cambridge,MA:Basil:Blackwell.

Friedman, T. L. 2005. The world is flat:Abrief history of the twenty-first century. NewYork: Farrar, Straus and Giroux.

Garcés-Conejos, P. \& Sánchez-Macarro, A. (1998). Scientific discourse as interaction: Scientific articles vs. popularizations. In A. Sánchez-Macarro \& R. Carter (Eds.), Linguistic choice across genres, pp. 173-190.

Goffman, Erving, 1967. Interaction Ritual: Essays on Face to Face Behavior. Aldine Publishing Company, Chicago.

Hall,E.T.(1959). The silent Language. New York: Doubleday

Janssens, M.,\&Brett, J. M. 2006. Cultural intelligence in global teams:Afusion model of collaboration. Group and Organization Management, 31: 124-153.

Lakoff, Robin, 1989. The limits of politeness: Therapeutic and courtroom discourse. Multilingua 8(2/3): 101-129.

Murphy, S. W. (1999). Politeness and self-presentation in writing center discourse. Unpublished doctoral dissertation, Texas A\&M University.

Myers, G. (1992). 'In this paper we report...' Speech acts and scientific facts. Journal of Pragmatics, 17:4, 295-313.

Ng, K.-Y., \& Earley, P. C. (2006). Culture + intelligence: Old constructs, new frontiers. Group \& Organization Management, 31(1), 4-19.

Nida,E.A.(1969).Science of translation: Language 45(P.483)

Saville-Troike, Muriel, 1996. The ethnography of communication. In: McKay, S., Hornberger, N. (Eds.), Sociolinguistics and Language Teaching. Cambridge University Press, Cambridge, pp. 351-382.

Schmidt, F. L., \& Hunter, J. E. (2000). Select on intelligence. In E. A. Locke (Ed.), The Blackwell handbook of organizational principles: 3-14. Oxford: Blackwell.

Scollon, R., \& Scollon, S. (1981). Narrative, literacy and face in interethnic communication. Norwood, NJ: Ablex Publishing Corporation.

Sternberg, R. J. 1986. A framework for understanding conceptions of intelligence. In R. J. Sternberg \&D.K.Detterman (Eds.), What is intelligence? Contemporary viewpoints on its nature and definition: 3-15. Norwood, NJ: Ablex.

Sternberg, R. J., \& Grigorenko, E. L. 2006. Cultural intelligence and successful intelligence. Group and Organization Management, 31: 27-39.

Thomas, D. C., \& Inkson, K. (2004). Cultural intelligence: People skills for global business. San Francisco: Berrett-Koehler.

Tracy, K.(1990). The many faces of facework.In H.Giles \& W.P.Robinson (Eds.),Handbook of Language and Social Psychology.(pp.209226).Chichester.John Wiley)

Triandis, H. C. (2006). Cultural intelligence in organizations. Group \& Organization Management, 31(1), $20-26$.

Appendix1: The Cultural Intelligence Scale (CQS)

Instruction: Read each statement and select the response that best describes your capabilities.

Select the answer that BEST describes you AS YOU REALLY ARE (1=strongly disagree; 7=strongly agree)

\section{CQ Factor Questionnaire Items}

\section{Metacognitive CQ:}

MC1 I am conscious of the cultural knowledge I use when interacting with people with different cultural backgrounds.

MC2 I adjust my cultural knowledge as I interact with people from a culture that is unfamiliar to me.

MC3 I am conscious of the cultural knowledge I apply to cross-cultural interactions.

MC4 I check the accuracy of my cultural knowledge as I interact with people from different cultures.

\section{Cognitive CQ:}

COG1 I know the legal and economic systems of other cultures.

COG2 I know the rules (e.g., vocabulary, grammar) of other languages.

COG3 I know the cultural values and religious beliefs of other cultures.

COG4 I know the marriage systems of other cultures.

COG5 I know the arts and crafts of other cultures.

COG6 I know the rules for expressing non-verbal behaviors in other cultures.

\section{Motivational CQ:}

MOT1 I enjoy interacting with people from different cultures.

MOT2 I am confident that I can socialize with locals in a culture that is unfamiliar to me.

MOT3 I am sure I can deal with the stresses of adjusting to a culture that is new to me.

MOT4 I enjoy living in cultures that are unfamiliar to me.

MOT5 I am confident that I can get accustomed to the shopping conditions in a different culture. 


\section{Behavioral CQ:}

BEH1 I change my verbal behavior (e.g., accent, tone) when a cross-cultural interaction requires it.

BEH2 I use pause and silence differently to suit different cross-cultural situations.

$\mathrm{BEH} 3$ I vary the rate of my speaking when a cross-cultural situation requires it.

BEH4 I change my non-verbal behavior when a cross-cultural situation requires it.

BEH5 I alter my facial expressions when a cross-cultural interaction requires it.

(c) Cultural Intelligence Center 2005. Used by permission of Cultural Intelligence Center.

Note. Use of this scale granted to academic researchers for research purposes only.

For information on using the scale for purposes other than academic research (e.g., consultants and non-academic organizations), please send an email to cquery@culturalq.com

\section{Appendix 2: The Situation and The Task}

\section{1) The Situation}

You have bought machinery from a foreign company which was supposed to ship your merchandise in two weeks time. You paid all the money before the delivery of the product. A month has passed but you haven't yet received it. So you want to write a letter or an e-mail chasing your merchandise and complaining to the company so as to receive your machinery as soon as possible. Moreover, ask for something in order to compensate for the inconvenience it has made for you.

\section{Your task}

Write a letter or an e-mail to the company to express your about the situation and also point out that you should be compensated for the delay in receipt of the product. 
